http://jmscr.igmpublication.org/home/

ISSN (e)-2347-176x ISSN (p) 2455-0450

crossref DOI: https://dx.doi.org/10.18535/jmscr/v7i7.41

\title{
Comparison of Diagnostic and Therapeutic Skills among Interns Trained in Dermatology and from those Untrained
}

\author{
Author \\ Dr Deepa Augustine \\ Assistant Professor, Department of Dermatology, Government Medical College, HMT Colony P.O \\ Ernakulam Kerala, India \\ *Corresponding Author \\ Dr Deepa Augustine
}

\begin{abstract}
Dermatology is slowly emerging as an exciting medical specialty in India .But the effectiveness of undergraduate curriculum in dermatology is questionable The Indian Medical Graduate lack a compulsory training in Dermatology during their internship. This present situation raised a question whether compulsory training in Dermatology during internship improves the diagnostic and therapeutic skills among Indian Medical graduate. A single institution descriptive study is conducted in the Department of Dermatology Government Medical College Ernakulam where two groups of interns of 40 each were randomly selected from a total of 100 interns who gave consent for the study by lottery method and were given a peer validated questionnaire and the scores were compared and statistically analysed. The group who had elective posting in dermatology had a definite increase in the knowledge score which was statistically significant. In this study it was concluded that a compulsory posting in dermatology during internship will definitely improve the therapeutic and diagnostic skills of interns and almost $100 \%$ of the interns who attended the study opted for a compulsory dermatology posting of at least 2 weeks.

Keywords: Dermatology, interns, diagnostic and therapeutic skills.
\end{abstract}

\section{Introduction}

Dermatology has become well entrenched in the undergraduate medical curriculum in India .However the effectiveness of the undergraduate dermatology curriculum is questionable. There are various problems in this context that need to be identified and addressed ${ }^{(1)}$

Dermatology has slowly but certainly emerged as one of the most exciting medical specialties in India. Post graduate teaching in Dermatology has advanced since its inception in 1940s. Unfortunately; undergraduate dermatology training is still lagging behind compared to many other broad specialties

Dermatology that is mastered by undergraduates during their medical training will underpin postgraduate education in foundation courses, medicine and general practice. Curriculum should foster skills in self-directed learning, application of knowledge and critical appraisal ${ }^{(2)}$. Analysis of student experiences has shown that an intended core curriculum is not sufficient to ensure that students are proficient in basic skills such as describing skin lesions ${ }^{(3)}$. If skills are deemed 
essential they should be taught and assessed. Undergraduate student should be able to diagnose common diseases of skin, hair, nail and mucosa syndromic approach of STI, common conditions like Leprosy, and when to refer patients ${ }^{(5)}$.

It is surprising that in a country like India in which skin disease form a very important part of community disease burden Dermatology is only an elective posting during internship. This issue has been raised previously and probably should continue to be pursued strongly to ensure that all interns have compulsory rotations in dermatology $y^{(3)}$. This study is undertaken to see whether there is a difference in the diagnostic and therapeutic skills among interns who had dermatology posting and those who didn't have dermatology posting

\section{Objective}

To compare the diagnostic and therapeutic skills among interns who had elective training in dermatology and those who didn't have training in dermatology

\section{Materials and Methods}

A Comparative descriptive study among interns is conducted in the Department of Dermatology in a teaching hospital in central Kerala. Among a total of 140 interns; 100 interns volunteered for the study. Among the 100 interns who gave consent for the study; 40 interns had finished their training in Dermatology. Among the rest of the 60 interns; 40 were randomly selected by lottery method to equalize the sample size. The interns who did not give consent and those who were absent on the day of data collection were excluded from the study. The study was conducted from Nov2015 to Feb 2016, in which data was collected in January after getting ethical clearance from the Institutional ethics committee. Two groups( trained and untrained) of 40 interns each were called on a particular day and were given a semi structured peer validated questionnaire constructed in English which contain both closed and open ended questions to assess the diagnostic and therapeutic skills of interns. The questionnaire has four parts which include personal details, posting details, knowledge questions and perception questions. Responses were collected and scoring of knowledge questions was calculated and an optimum score of 15 out of 25 was kept as the cut off and the scores among the two groups were compared and statistically analysed.

\section{Analysis}

Descriptive analysis of the variables is listed in frequency tables and graphically represented. Bivariate analysis is performed calculating the proportion of the outcome variable .Odds ratio is calculated and interpreted. Statistical testing is done using chi square test at $95 \%$ confidence level and $\mathrm{p}$ value of .05 and the statistical significance is interpreted. The mean score of the knowledge outcome was also analysed using two sample $t$ test with welch correction for homogenesity and was found to be statistically significant.

\section{Results and Interpretation of the Project}

Comparison of knowledge among two groups

Table 1 Knowledge score in elective trained group

\begin{tabular}{|l|c|c|}
\hline Knowledge Score & Frequency & Percentage \\
\hline Less than or equal to 15 & 20 & 50 \\
\hline$>15$ & 20 & 50 \\
\hline Total & 40 & 100 \\
\hline
\end{tabular}

$50 \%$ of interns who had elective training in Dermatology scored above of 15 compared to $17.5 \%$ in the untrained group. $40 \%$ of trained interns who took part in the study opted for 2 weeks of compulsory intern ship in dermatology whereas $35 \%$ opted for 4 weeks and the rest $10 \%$ for 3 weeks of training in Dermatology during internship.

Most of the interns of the untrained group were of 23 years and 24 years $(32.55 \%)$ respectively. 


\section{JMSCR Vol||07||Issue ||07||Page 206-210||July}

Knowledge Score in the Untrained Group

Table-2 Knowledge score in the untrained group

\begin{tabular}{|l|c|c|}
\hline Knowledge & Frequency & Percentage \\
\hline$\leq 15$ & 33 & 82.5 \\
\hline$>15$ & 7 & 17.5 \\
\hline TOTAL & 40 & 100 \\
\hline
\end{tabular}

$82.5 \%$ of the interns trained in Dermatology had a score less than or equal to 15 out of 25 and only $17.5 \%$ had a score above 15 .
Comparison of Knowledge in the two Groups

Table 3 Comparison of knowledge in the two groups

\begin{tabular}{|l|c|c|c|}
\hline \multirow{2}{*}{ Posting } & \multicolumn{2}{|c|}{ Knowledge score } & \multirow{2}{*}{ total } \\
\cline { 2 - 3 } & $>15$ & $>\_15$ & \\
\hline Elective & 20 & 20 & 40 \\
\hline Nonelective & 7 & 33 & 40 \\
\hline Total & 27 & 53 & 80 \\
\hline
\end{tabular}

OR-4.7, Chi-square -9.5, $\mathrm{p}$ value $<0.05$ which is statistically significant.

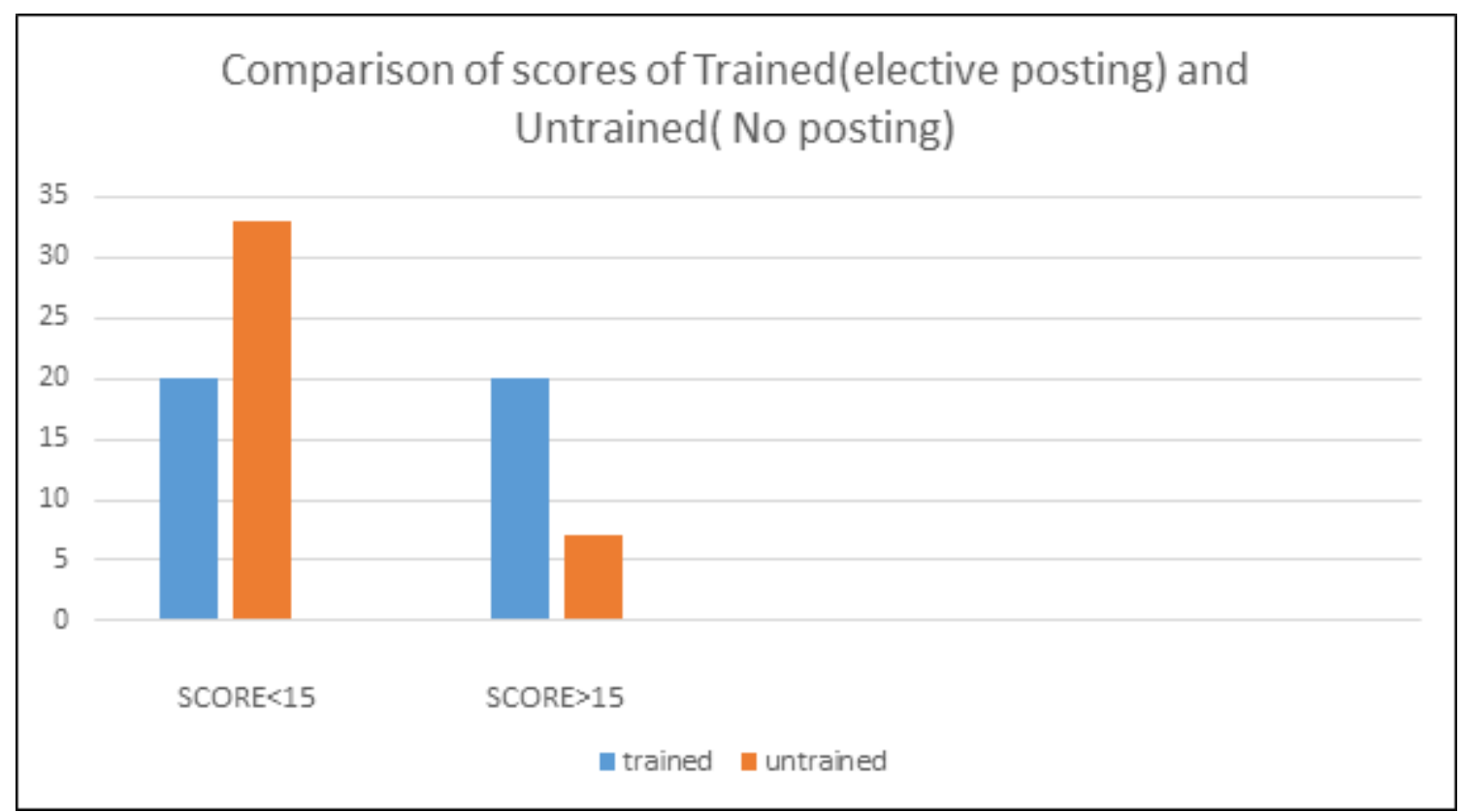

Graph-1

Effect of dermatology elective on interns

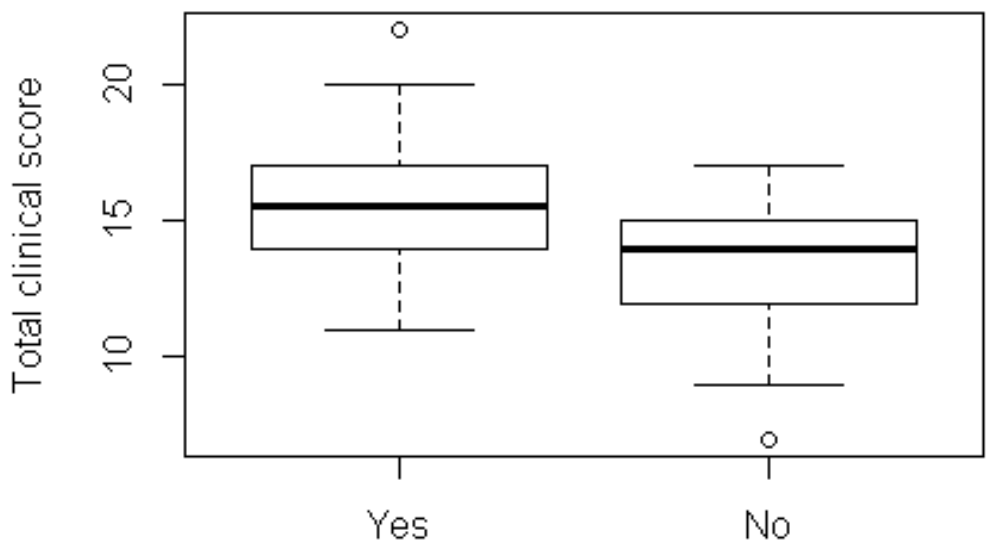

Underwent elective dermatology training

Graph 2 
Two sample $\mathrm{t}$ tests with Welch correction for homogenesity was done, t-3.7987; pvalue0.0002865 which is statistically significant. Mean score in trained group was 13.450 as compared to mean score in untrained group which was 13.450 which also showed statistical significance.

\section{Perception Questions}

All the interns irrespective of whether they were trained or not; opined that a compulsory training in dermatology is essential during internship. Different suggestions came from the interns about the duration of training that is required in dermatology to acquire the necessary skills to manage common dermatological conditions. $45 \%$ of the interns were for 2 weeks of compulsory internship in dermatology where as another 37.5 $\%$ opted for 4 weeks duration.

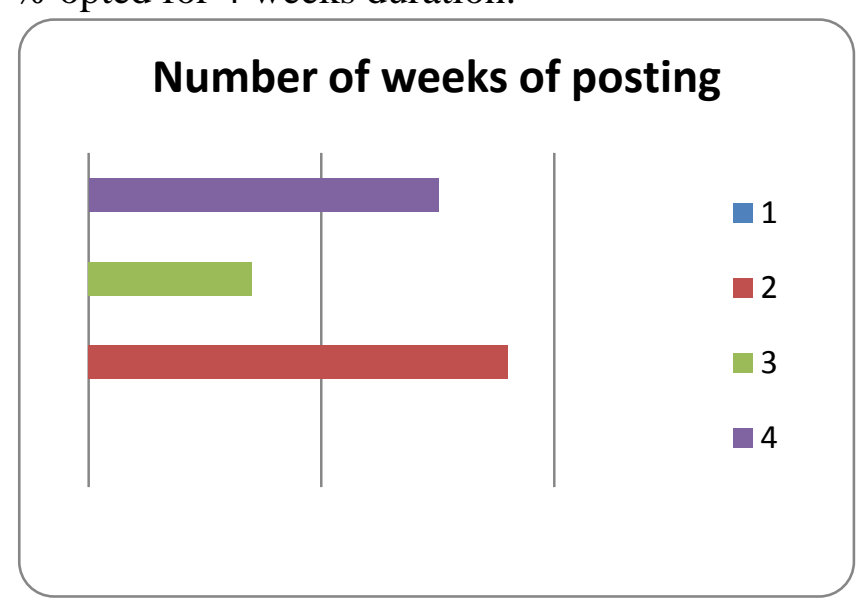

Graph 3

\section{Discussion}

Majority of interns in both groups were females $(67.5 \%)$ in trained and $75 \%$ in untrained group which is at par with a general trend of a female preponderance in undergraduate medical education. There was a definite increase in the percentage of interns who scored above the cut off score of 15 out of 25 which was $50 \%$ in the trained group, compared to $17.5 \%$ in the untrained group. $100 \%$ of the interns in both groups opted for a compulsory internship in dermatology. Majority of interns in the two groups suggested that they should have more than two weeks of dermatology posting during the internship. In a study conducted by Barbera Gerbert et al; primary care physicians failed to diagnose malignant melanoma $40 \%$ of times, and doubted whether the primary training given to medical students were sufficient to increase their diagnostic skills. ${ }^{(6)}$ Another study by Pariser et al; which analyzes the errors made by primary care physicians in diagnosing common cutaneous problems. According to this study most of the primary care physicians tend to over diagnose common infectious dermatoses and under diagnose inflammatory dermatoses. ${ }^{(8)}$ In a study conducted in the Dermatology Department of King Fahad Hospital of the University of Alkhobar Saudi Arabia among rotating interns there was a sufficient improvement in the diagnostic skills after an elective training of 4 weeks in dermatology ${ }^{(9)}$. During the undergraduate period there is 2 weeks training in Dermatology in the 4th semester and 4 weeks in the 5th semesters .But during internship only those interns who electively opt for dermatology posting gets trained in dermatology. This adversely affect the competency of primary care physicians who are dealing with dermatology cases leading to misdiagnosis, over diagnosis and injudicious use of topical medications .There is shortage of sufficient literature in this regard since dermatology is considered as a minor specialty

\section{Conclusion}

In this study though conducted within a short period showed a definite increase in the knowledge score among interns who had two weeks of elective training in dermatology. Hence according to our study a compulsory training of two weeks during the regular internship can definitely increase the diagnostic and therapeutic abilities of interns. Such training will definitely make the interns equipped to diagnose and treat common dermatological problems which will in turn fulfill the requirements as per the MCI curriculum to become a successful Indian medical graduate. 


\section{JMSCR Vol||07||Issue||07||Page 206-210||July}

\section{Recommendations}

More studies are needed with a large sample size over the coming years to emphasize the importance and effectiveness of including dermatology as a compulsory training in the curriculum during internship.

\section{References}

1. Mary AnJohnsonMD Resident C Davis Dermatology, An assessment of diagnostic and therapeutic skills acquired after dermatology elective posting AAD U059 Semi annual Meeting of the DERMATOLOGY TEACHERS EXCHANGE GROUP

2. Kaliyadan F1, Manoj J, Dharmaratnam AD, Sreekanth G. Self learning modules in dermatology-a pilot study J EurAcad Dermatol Venereol 2010Jun; 24(6):655-60

3. Feroz Kaliyadn, Undergraduate dermatology teaching in India - need for a change Ijdvl2010Vol 76 ; 5)455-457

4. ClaytonR, Periera R, BurgeS, Defining the dermatological content of the undergraduate medical curriculum: a modified Delphi study $\mathrm{Br}$ J Dermatol 2006; 155:137-144

5. MCI Regulations on graduate medical education 2012

6. Gerbert B, Maurer T, Berger T, Pantilat S, McPhee SJ, Wolff $M$ et al. Primary care physician as gatekeeper in managed care. Arch Dermatol. 1996; 132: 1030-1038.

7. Enk C, Gilead L, Smolovich I, Cohen R. Diagnostic performance and retention of acquired skills after dermatology elective. Int J Dermatol 2003; 42:812-815.

8. Cassileth BR, Clark WH Jr, Lusk EJ Pariser RJ \& Pariser DM. Primary care physicians' errors in handling cutaneous disorders: a prospective study. J Am Acad Dermatol. 1987; 17: 239- 245.
9. Bukhari, O AlAkloby Evaluation of Diagnostic Skills of Interns Electively Rotating At the Dermatology Department of King Fahad Hospital of the University in Alkhobar, Saudi Arabia the Internet Journal of Dermatology; Volume 5: Number 2. 